\title{
Epidemiological pattern of leprosy in Ethiopia: a review of the control programmes
}

\author{
D BERHE, ${ }^{*} \mathrm{R} T$ HAIMANOT, $\dagger \mathrm{T}$ TEDLA $\ddagger \&$ \\ T TADDESSE $\S$ \\ *Leprosy Control Division, All Africa Leprosy and Rehabilitation \\ Training Centre (ALERT), PO Box 165, Addis Ababa, Ethiopia; \\ $\dagger$ Department of Internal Medicine, Faculty of Medicine, Addis \\ Ababa University, Ethiopia; $\$$ National Le prosy Control, Ministry of \\ Health, Peoples Democratic Republic of Ethiopia, Addis Ababa, \\ Ethiopia; §Hospital Services Division, ALERT
}

\section{Accepted for publication 15 January 1990}

\begin{abstract}
Summary Leprosy control started in a limited area of Ethiopia in 1956. Extended coverage of the country was achieved in the early seventies. Review of the data from the control projects since 1976 revealed that leprosy is a disease of the Ethiopian highlands where prevalence rates as high as 7 per thousand have been recorded in some provinces, while the cumulative national average for the last 13 years was 2.6 per thousand. The paucibacillary form was predominant. However, unlike other African countries, a relatively high proportion of multibacillary leprosy was found in Ethiopia. The male-to-female ratio was $2: 1$ with the highest prevalence in the 15-44 years age bracket. Detection rates for new cases have shown a gradual decline since 1982, a year before multiple drug therapy (MDT) was introduced into the country. For the last 5 years the number of new cases has stabilized at $4700 / y e a r$. These trends probably reflect a general reduction in the prevalence of leprosy in the country, while the conspicuous decline in 1982 is most likely related to discharge of cases during screening before MDT. The new villagization policy of Ethiopia with its effective reorganization of the populations is believed to make control programmes and supervision of MDT easier and presumably more effective. Similarly, more reliable prevalence and incidence studies could be undertaken with success.
\end{abstract}

\section{Introduction}

Over 10 million people in the world are estimated to have leprosy. Only 50\% are registered cases and of these, $12 \%$ are found in Africa. Ethiopia belongs to the endemic regions of the continent, with prevalence rates of $1 \cdot 0-1 \cdot 9 .{ }^{1}$ Situated in the north-eastern part of the continent, Ethiopia covers an area of 1.25 million sq.km, and has a population of 46 million. ${ }^{2}$ The topography of the country is dominated by the high central plateau (2000- 
3000 metres), which is split diagonally by the Rift Valley. In 1977 Cap \& Banjaw 3 estimated that less than $50 \%$ of the leprosy patients in the endemic highland regions were registered for treatment. Thus, in Ethiopia, leprosy poses a major national public health problem with serious medicosocial consequences.

The data available on the prevalence of the disease are far from complete. Many rural parts of the country are not easily accessible, and lack basic medical services. In addition, because of social stigma and ostracism, those affected by the disease may fail to seek medical attention. However, in Ethiopia, compared with other infectious diseases leprosy has received significant attention from government and international agencies. Thus, there has been reliable registration of cases by leprosy control programmes that have been operational in the country since 1969.

This study was designed to review the epidemiology of the disease in Ethiopia, based on accumulated data from the control programmes. It is also intended to give some predictive forecast on the general trends in the prevalence of the disease as related to the leprosy control activities in the country.

\section{Materials and methods}

\section{HISTORICAL BACKGROUND AND ORGANIZATION OF LEPROSY CONTROL PROGRAMMES}

Organized leprosy treatment was started in 1934 at the Princess Zenebe Work Hospital, which was built on the outskirts of Addis Ababa by the Sudan Interior Mission (SIM), under the auspices of the Ethiopian Ministry of Health. This modest nucleus of leprosy care expanded over the years into a leprosy hospital with facilities for diagnosis and treatment, as well as a base for leprosy control activities. In the 1960s other smaller leprosaria were established in the northern, central and southern parts of the country, with emphasis on treatment and agricultural rehabilitation of the leprosy patients and their families.

A leprosy control programme was effectively started in 1956 with the policy of 'bringing leprosy treatment as near to the patient's home as possible'. ${ }^{4}$ Accordingly, in estimated low and moderate prevalence areas (1-4 and 5-9 per thousand respectively), the treatment and follow-up of patients was carried out by the existing basic health services, supervised by the provincial medical officer with guidance and coordination from the National Leprosy Control Programme. In areas with high prevalence rates (10 per thousand), the basic medical service staff was supplemented by a specially trained leprosy health worker. In addition to his duties in the basic medical services, whenever possible the leprosy health worker is made responsible for three to five leprosy treatment centres situated in a market-place, not far from his post. The overall supervision and coordination of the control activities are under the provincial leprosy officer, who is attached to the Provincial Health Department.

In 1965, with international supporting agencies, the leprosy hospital in Addis Ababa was turned into the All Africa Leprosy and Rehabilitation Training Centre (ALERT), with the aim, 'to train men and women in all aspects of leprosy, with special emphasis on control, treatment and rehabilitation for work in Africa'. 5 As part of a national antileprosy campaign, and with the need for a model for training purposes, ALERT took up the leprosy control programme in Ethiopia's central administrative region of Shoa and Addis Ababa town. 
All patients received monotherapy with dapsone until 1970, when the first cases of resistance were reported. ${ }^{6}$ Subsequently, multiple drugs were used in the management of selected resistant cases. Multiple drug therapy (MDT), as recommended by $\mathrm{WHO},{ }^{7}$ was officially adopted by the Ethiopian leprosy control programmes in 1983. In this study, the 13 years' records, since 1976, of the National and ALERT leprosy control programmes are reviewed. The Ethiopian Central Statistics Office provided the national census figures.

\section{Results}

The age and sex distribution of the leprosy patients, as shown in Table 1, is based on the records of the ALERT Leprosy Control Programme (1984-88). Ten per cent were under 15 years of age. The age group 15-44 was predominantly affected $(70 \%)$. The male-tofemale ratio was $2: 1$. This distribution is similar to that reported by Adamu \& Naafs. ${ }^{8}$

Analysis of the diagnostic classification of leprosy over the last 5 years, using a modification of the Ridley-Jopling classification, ${ }^{9}$ revealed borderline-tuberculoid leprosy to be the commonest $(38 \cdot 3 \%)$, followed by borderline-lepromatous leprosy $(27 \cdot 6 \%)$ (Table 1). In the classification of leprosy used by the leprosy control programmes in Ethiopia, the indeterminate (I) and borderline (BB) groups were not used. The age distribution of newly registered cases has remained relatively constant while the proportion of lepromatous patients has shown an increase over successive years since 1986 (Table 2).

Figures 1 and 2 show the detection rate of leprosy from the Shoa Administrative Region and the whole country respectively over the last 13 years. One sees a definite decline of detection rates starting in 1982. The decline forms a plateau over the last 5 years (Figure 2), at an average of 4700 new cases per year, ${ }^{10}$ The number of new cases will

Table 1. Distribution of new leprosy cases by age, sex and classification in the Shoa Administrative Region (198488)

\begin{tabular}{|c|c|c|c|c|c|c|c|c|c|c|c|c|c|c|}
\hline \multirow{2}{*}{$\begin{array}{l}\text { Age } \\
\text { group } \\
\text { (years) }\end{array}$} & \multicolumn{2}{|c|}{$\mathrm{TT}$} & \multicolumn{2}{|c|}{ BT } & \multicolumn{2}{|c|}{ BL } & \multicolumn{2}{|c|}{$\mathrm{LL}$} & \multicolumn{6}{|c|}{ Total } \\
\hline & $\mathbf{M}$ & $\mathrm{F}$ & $\mathbf{M}$ & $\mathrm{F}$ & $\mathbf{M}$ & $\mathrm{F}$ & M & $\mathrm{F}$ & $\mathbf{M}$ & $\%$ & $\mathrm{~F}$ & $\%$ & $M+F$ & $\%$ \\
\hline $0-14$ & 79 & 46 & 128 & 100 & 71 & 56 & 27 & 22 & 305 & $5 \cdot 9$ & 224 & $4 \cdot 4$ & 529 & $10 \cdot 3$ \\
\hline $15-24$ & 139 & 76 & 300 & 188 & 201 & 120 & 110 & 70 & 750 & $14 \cdot 6$ & 454 & $8 \cdot 9$ & 1204 & $23 \cdot 5$ \\
\hline $25-34$ & 129 & 87 & 264 & 169 & 256 & 132 & 144 & 85 & 793 & $15 \cdot 5$ & 473 & $9 \cdot 2$ & 1266 & $24 \cdot 7$ \\
\hline $35-44$ & 119 & 47 & 288 & 154 & 208 & 74 & 154 & 70 & 769 & $15 \cdot 0$ & 345 & $6 \cdot 7$ & 1114 & $21 \cdot 7$ \\
\hline $45-54$ & 73 & 32 & 155 & 62 & 128 & 51 & 73 & 39 & 429 & $8 \cdot 4$ & 184 & $3 \cdot 6$ & 613 & $11 \cdot 9$ \\
\hline $55+$ & 47 & 27 & 106 & 49 & 90 & 29 & 42 & 15 & 285 & $5 \cdot 5$ & 120 & $2 \cdot 3$ & 405 & $7 \cdot 9$ \\
\hline Total & 586 & 315 & 1241 & 722 & 954 & 462 & 550 & 301 & 3331 & $64 \cdot 9$ & 1800 & $35 \cdot 1$ & 5131 & $100 \cdot 0$ \\
\hline$\%$ & $11 \cdot 4$ & $6 \cdot 1$ & $24 \cdot 2$ & $14 \cdot 1$ & $18 \cdot 6$ & $9 \cdot 0$ & $10 \cdot 7$ & $5 \cdot 9$ & & & & & & \\
\hline Total & \multicolumn{2}{|c|}{901} & \multicolumn{2}{|c|}{1963} & \multicolumn{2}{|c|}{1416} & \multicolumn{2}{|c|}{851} & & & & & & \\
\hline$\%$ & \multicolumn{2}{|c|}{$17 \cdot 6$} & \multicolumn{2}{|c|}{$38 \cdot 2$} & \multicolumn{2}{|c|}{$27 \cdot 6$} & \multicolumn{2}{|c|}{$16 \cdot 6$} & & & & & & \\
\hline
\end{tabular}


Table 2. Yearly distribution of new leprosy cases by age and classification in Shoa Administrative Region (1984-88)

\begin{tabular}{|c|c|c|c|c|c|c|c|c|c|c|c|c|}
\hline \multirow{3}{*}{$\begin{array}{l}\text { Age } \\
\text { group } \\
\text { (years) }\end{array}$} & \multicolumn{6}{|c|}{1984} & \multicolumn{6}{|c|}{1985} \\
\hline & \multirow[b]{2}{*}{$\mathrm{TT}$} & \multirow[b]{2}{*}{ BT } & \multirow[b]{2}{*}{ BL } & \multirow[b]{2}{*}{$\mathrm{LL}$} & \multicolumn{2}{|c|}{ Total } & \multirow[b]{2}{*}{$\mathrm{TT}$} & \multirow[b]{2}{*}{ BT } & \multirow[b]{2}{*}{$\mathrm{BL}$} & \multirow[b]{2}{*}{ LL } & \multicolumn{2}{|c|}{ Total } \\
\hline & & & & & No. & $\%$ & & & & & No. & $\%$ \\
\hline $0-14$ & 35 & 35 & 25 & 17 & 112 & $9 \cdot 3$ & 23 & 30 & 22 & 9 & 84 & $9 \cdot 5$ \\
\hline $15-24$ & 91 & 68 & 57 & 47 & 263 & 21.9 & 39 & 98 & 40 & 30 & 207 & $23 \cdot 5$ \\
\hline $25-34$ & 82 & 57 & 83 & 49 & 271 & $22 \cdot 6$ & 43 & 82 & 75 & 51 & 251 & $28 \cdot 4$ \\
\hline $35-44$ & 80 & 75 & 63 & 65 & 283 & $23 \cdot 6$ & 29 & 65 & 48 & 43 & 185 & $21 \cdot 0$ \\
\hline $45-54$ & 50 & 32 & 38 & 31 & 151 & $12 \cdot 6$ & 22 & 27 & 28 & 17 & 94 & $10 \cdot 7$ \\
\hline $55+$ & 37 & 31 & 29 & 23 & 120 & $10 \cdot 0$ & 19 & 18 & 14 & 10 & 61 & 6.9 \\
\hline Total & 375 & 298 & 295 & 232 & 1200 & $100 \cdot 0$ & 175 & 320 & 227 & 160 & 882 & $100 \cdot 0$ \\
\hline$\%$ & $31 \cdot 3$ & $24 \cdot 8$ & $24 \cdot 6$ & $19 \cdot 3$ & 100 & - & $19 \cdot 9$ & $36 \cdot 3$ & $25 \cdot 7$ & $18 \cdot 1$ & $100 \cdot 0$ & - \\
\hline \multirow{3}{*}{$\begin{array}{l}\text { Age } \\
\text { group } \\
\text { (years) }\end{array}$} & \multicolumn{6}{|c|}{1986} & \multicolumn{6}{|c|}{1987} \\
\hline & \multirow[b]{2}{*}{$\mathrm{TT}$} & \multirow[b]{2}{*}{ BT } & \multirow[b]{2}{*}{ BL } & \multirow[b]{2}{*}{$\mathrm{LL}$} & \multicolumn{2}{|c|}{ Total } & \multirow[b]{2}{*}{$\mathrm{TT}$} & \multirow[b]{2}{*}{ BT } & \multirow[b]{2}{*}{$\mathrm{BL}$} & \multirow[b]{2}{*}{ LL } & \multicolumn{2}{|c|}{ Total } \\
\hline & & & & & No. & $\%$ & & & & & No. & $\%$ \\
\hline $0-14$ & 26 & 61 & 21 & 11 & 119 & $11 \cdot 8$ & 19 & 48 & 23 & 6 & 96 & $9 \cdot 5$ \\
\hline $15-24$ & 35 & 101 & 57 & 28 & 221 & $22 \cdot 0$ & 27 & 110 & 80 & 36 & 253 & $25 \cdot 0$ \\
\hline $25-34$ & 37 & 85 & 62 & 38 & 222 & $22 \cdot 1$ & 32 & 117 & 78 & 45 & 272 & $26 \cdot 9$ \\
\hline $35-44$ & 36 & 93 & 50 & 36 & 215 & $21 \cdot 4$ & 12 & 98 & 58 & 36 & 204 & $20 \cdot 2$ \\
\hline $45-54$ & 14 & 58 & 39 & 17 & 128 & $12 \cdot 7$ & 8 & 57 & 37 & 22 & 124 & $12 \cdot 2$ \\
\hline $55+$ & 5 & 50 & 36 & 10 & 101 & $10 \cdot 0$ & 3 & 33 & 18 & 9 & 63 & $6 \cdot 2$ \\
\hline Total & 153 & 448 & 265 & 140 & 1006 & $100 \cdot 0$ & 101 & 463 & 294 & 154 & 1012 & $100 \cdot 0$ \\
\hline$\%$ & $15 \cdot 2$ & $44 \cdot 5$ & $26 \cdot 3$ & 13.9 & 99.9 & - & $10 \cdot 0$ & $45 \cdot 8$ & $29 \cdot 0$ & $15 \cdot 2$ & $100 \cdot 0$ & \\
\hline
\end{tabular}

\begin{tabular}{lrrrrrr}
\hline & \multicolumn{7}{c}{1988} \\
\cline { 2 - 7 } $\begin{array}{l}\text { Age } \\
\text { group } \\
\text { (years) }\end{array}$ & TT & BT & BL & LL & No. & $\%$ \\
\hline $0-14$ & 22 & 54 & 36 & 6 & 118 & $11 \cdot 4$ \\
\hline $15-24$ & 23 & 111 & 87 & 39 & 260 & $25 \cdot 2$ \\
\hline $25-34$ & 22 & 92 & 90 & 46 & 250 & $24 \cdot 3$ \\
\hline $35-44$ & 9 & 111 & 63 & 44 & 227 & $22 \cdot 0$ \\
\hline $45-54$ & 11 & 43 & 37 & 25 & 116 & $11 \cdot 3$ \\
\hline $55+$ & 10 & 23 & 22 & 5 & 60 & $5 \cdot 8$ \\
\hline Total & 97 & 434 & 335 & 165 & 1031 & $100 \cdot 0$ \\
\hline$\%$ & $9 \cdot 4$ & $42 \cdot 1$ & $32 \cdot 5$ & $16 \cdot 0$ & $100 \cdot 0$ & \\
\hline$\%$
\end{tabular}




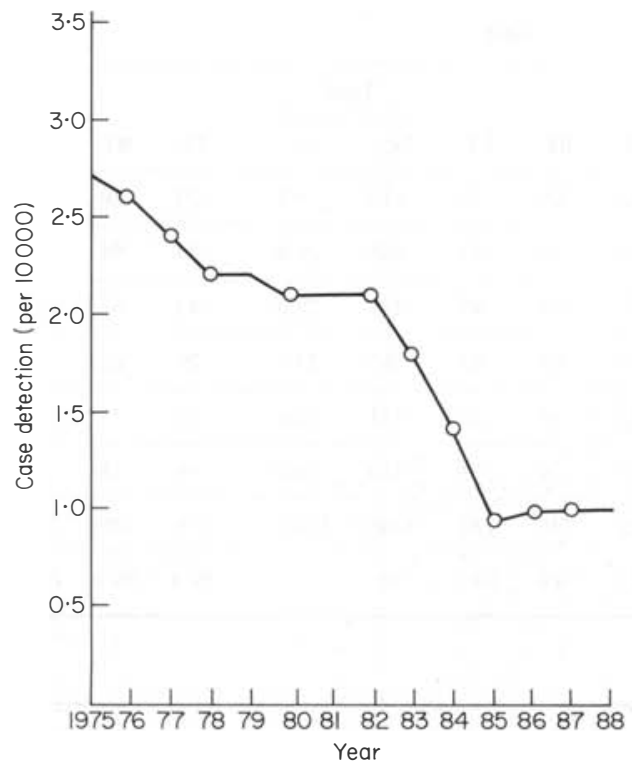

Figure 1. Leprosy case detection rate in Shoa Administrative Region, 1975-88. (Source: Annual Reports, ALERT Leprosy Control.)

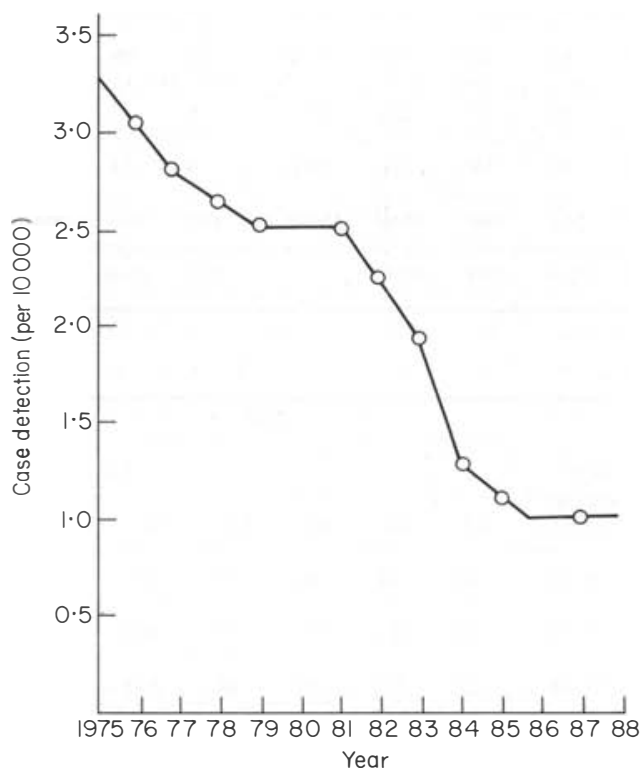

Figure 2. Leprosy case detection rate in Ethiopia, 1975-88. (Source: Annual Reports, National Leprosy Control Project.) 


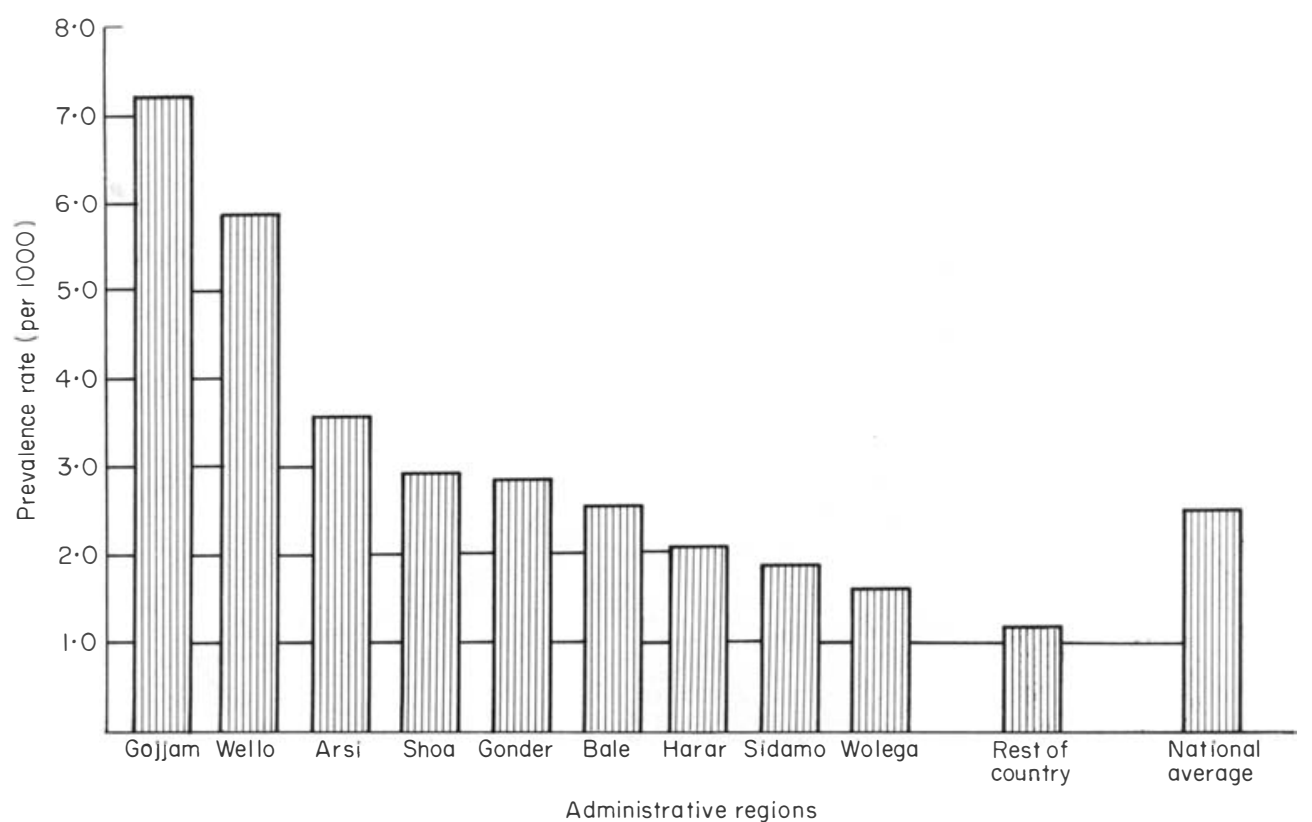

Figure 3. Prevalence rate of leprosy in the different administrative regions of Ethiopia. (Source: Annual Reports (1975-81), National Leprosy Control Project.)

probably remain at the same level for some years to come, until the real effect of multiple drug therapy is expected to halt the transmission of the disease.

Figure 3 represents the prevalence pattern in the different administrative regions, as compared to the national average of 2.6 per thousand over 6 years (1976-81) two years prior to the start of MDT. The prevalence of leprosy is highest in Gojjam and Wello (north-west and north-east of the country, respectively) while moderate rates are observed in Arsi, Shoa, Gonder and Bale (respectively of south, central, north and southeast Ethiopia). As shown in Figure 4, these hyperendemic and endemic areas occupy the highland regions of Ethiopia. The prevalence rates in the lowlands of the Rift Valley are very low, except in some densely populated areas (the districts of Yifat and Timuga, and Haikoch and Butajira) within the Shoa Administrative Region, where hyperendemicity (prevalence rates 1.5-7.8 per thousand) has been documented by the ALERT Leprosy Control programme in the years 1981 to $1986 .{ }^{11}$

\section{Discussion}

Epidemiological studies of leprosy have been very difficult to make for many reasons, particularly because leprosy patients are self-selected groups, not representative of the population as a whole. ${ }^{12}$ Previous prevalence and incidence studies have used both physical examination and verbal recall in data collection and analysis. These methods have been criticized for bias and variability. Population-based studies to determine 


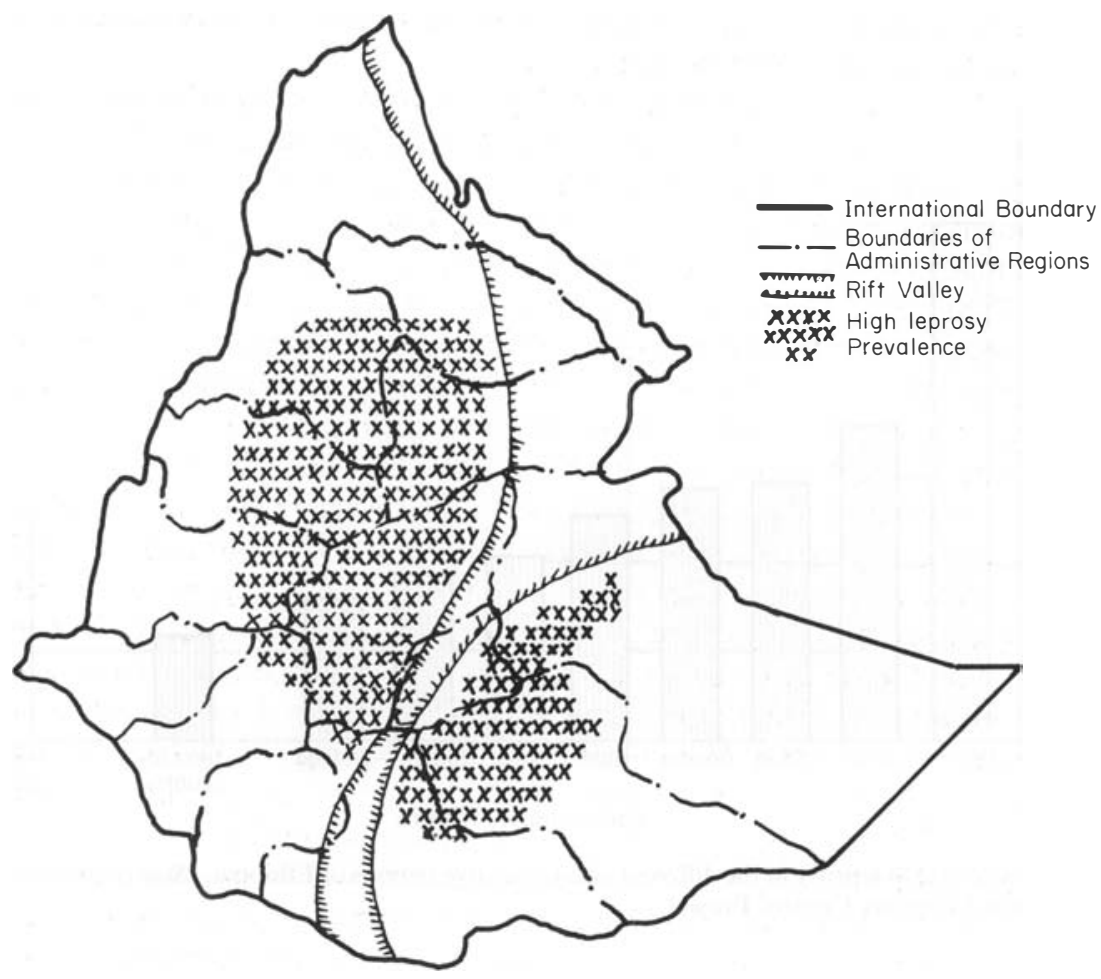

Scale: $5,000,000$

Figure 4. Ethiopia - showing areas of high leprosy prevalence corresponding to the highland regions of the country.

prevalence are very few and certainly not yet available for Ethiopia. We are therefore forced to rely on the information gathered by Control Projects.

Leprosy in Africa is characterized by a low proportion of lepromatous cases. ${ }^{13}$ However, as shown in this study, there is a significantly high prevalence of the multibacillary form of leprosy in Ethiopia, sufficient to make the distribution different from the rest of Africa.

As observed by Schaller, ${ }^{14}$ and later Cap \& Banjaw, ${ }^{3}$ this study clearly demonstrates that leprosy is endemic over the highland regions of the country, but also affects a few of the districts of the Shoa Administrative Region (central Ethiopia) which lie either bordering or within the Rift Valley.

One study ${ }^{15}$ found a high prevalence of leprosy in the lowland Mendi district within the Blue Nile Valley of western Ethiopia. It suggested that the previous endemic leprosy situation in the highlands had been overshadowed by tuberculosis prevalence; nevertheless, there was an ongoing leprosy epidemic in the lowlands.

Except for these isolated endemic areas, for Ethiopia at large, leprosy is a disease of the highland regions. However, it is interesting that this geographical distribution is contrary to the findings of one study ${ }^{16}$ in Malawi, which found a five-fold increase in the 
prevalence rates of the Rift Valley compared with the Central African plateau. We have been unable to explain this obvious difference.

The gradual decline of the prevalence of leprosy as observed in this study, may be a welcome result of the effort of the well-organized control projects, mainly with dapsone monotherapy. However, among others, Meade ${ }^{17}$ has argued that secondary prevention of leprosy, as practiced in the Ethiopian or Malawian Control Programmes, is unlikely to contribute much towards the ultimate eradication of leprosy. Nevertheless, we see a definite decline of leprosy prevalence in Ethiopia, as registered both by the National and ALERT Leprosy Control Programmes. Similar trends expressed in a significant reduction of prevalence rates have been observed in Thailand, ${ }^{18}$ and Burma, ${ }^{19}$ Ponnighaus $\&$ Boerrigter, who have also registered declines in detection rates in Malawi, believe that the trend may actually reflect a genuine decline in the incidence rates. ${ }^{16}$ Although analysis of the 5 years data from the Shoa Administrative Region did not show an obvious shift towards older age groups, the increase in lepromatous rates over the last 3 years (1986-88) may reflect a decline in the incidence of leprosy in Ethiopia as suggested by Irgens. ${ }^{20}$

The conspicuous start of the decline in registered and new cases as well as in the prevalence of the disease in 1982 has attracted attention because it coincided with the launching of multiple drug therapy in the country. This was not definitely a direct effect of MDT, however, because MDT was effectively started only in 1983. However, as part of the preparations for the start of the MDT programme, there was a general reorganization and up-grading of the leprosy clinics in terms of diagnosis and treatment. The leprosy workers were re-educated and motivated. This, coupled with new awareness created in patients, resulted in release from treatment of many patients, particularly the paucibacillary patients who were found to have been adequately treated, provided the following criteria were met:

(a) the disease was clinically inactive and bacteriologically negative; and

(b) there was a cumulative attendance of $75 \%$ of 5 year's treatment of paucibacillary patients, and of 10 year's treatment of multibacillary patients.

One study ${ }^{21}$ using a hypothetical mode, shows that there will be significant falls in prevalence rates in the first 5 years of the introduction of MDT into leprosy endemic districts, mainly as a result of discharge of cases during screening and due to shortening of duration of treatment. In his extensive editorial review of the common features in the decline of leprosy epidemics, Davey ${ }^{22}$ pointed to the voluntary isolation of infective and potentially infective leprosy cases on dapsone treatment, and the creation of an atmosphere of mutual trust and cooperation between patients and those engaged in control programmes, with strong public health education, as the most essential elements of a successful policy of leprosy control. In this context, in present-day Ethiopia, much is to be gained from the recent introduction and active implementation of villagization programmes, in which previously scattered populations have been brought together in order to establish centralized services. This will certainly be most useful in the early detection of leprosy cases. With their well-organized and regimented administrative structures, these villages should make the diagnosis, treatment and follow-up of leprosy cases more efficient. Health education should also be easily propagated and much more effective.

It is therefore suggested that those in leprosy control work might exploit the good organization of the Peasant' Associations. An additional advantage of these organized 
villages is the possibility of conducting prevalence and incidence studies with limited resources. Such studies should be both accurate and reliable, because they will be based on a stable and controlled population whose social and economical characteristics are well defined.

In spite of Ethiopia's other priorities for dealing with communicable diseases of higher prevalences, leprosy has gained recognition and an advantageous position, with relatively good financial resources for it's control activities. Working closely with the basic medical services and the Peasant Associations, an operationally efficient control programme, with active case detection and MDT, can achieve a further and more significant reduction in the prevalence of leprosy in the country.

\section{References}

WHO. A Guide to leprosy control. WHO; Geneva, 1988.

Ethiopia, Central Statistical Office. People's Democratic Republic of Ethiopia: Facts and figures. 1986.

3 Cap JA, Banjaw M. Leprosy in Ethiopia. German Leprosy Relief Association (DAHW), Wurzburg II/West Germany, 1977.

${ }^{4}$ Price EW. Leprosy control in Ethiopia-policy documents. Addis Ababa, Ethiopia, 1977.

5 Widad KM. Historical outline of ALERT. Ethiop Med J, 1986; 24: Suppl. 1, 19-25.

${ }^{6}$ Pearson JMH, Haile GS, Barnetson R StC, Rees RJW. Dapsone-resistant leprosy in Ethiopia. Lepr Rev, 1979; 50: 183-99.

WHO. Chemotherapy of leprosy for control programmes. WHO Technical Report Series No. 675, 1982.

Adamu A, Naafs B. Theage at onset of overt leprosy among patients presenting at the Addis Ababa Leprosy Hospital. Ethiop Med J, 1982; 20: 117-24.

9 Ridley DS, Jopling WH. Classification of leprosy according to immunity. A five-group system. Int J Lepr, 1966; 34: 255-73.

10 National Leprosy Control Project. Ministry of Health, Addis Ababa, Ethiopia. Annual Report, 1988.

11 All Africa Leprosy and Rehabilitation Training Centre (ALERT). Leprosy Control Project, Addis Ababa, Ethiopia. Annual Report, 1987.

12 Bryceson A, Pfaltzgraff RE. Leprosy. London: Churchill Livingstone, 1979, p 126.

13 Cap JA. The epidemiological situation in Africa. Lepr Rev, 1981; 52: Suppl 1, 53-60.

14 Schaller KF, Kuls W. Ethiopia. A Geomedical Monograph. Springer Verlag: Berlin, Heidelberg and New York, 1972.

15 Gundersen SG. Leprosy and tuberculosis in the Blue Nile valley of Western Ethiopia. Lepr Rev, 1987; 58, 1140.

16 Ponnighaus JM, Boerrigter G. Ten years' leprosy work in Malawii (central Africa)-II. Patterns of endemicity since 1973. Lepr Rev, 1986; 57: 221-36.

17 Meade TW. Epidemiology and leprosy control. Lepr Rev, 1971; 42: 14-25.

18 Pakdi AC, Sanyolorn CK, Seal KS. Some results from sixteen years of leprosy control work in the Kohn Kaeh province of N.E. Thailand. Lepr Rev, 1974; 45: 205-10.

19 Kyaw L, Zuiderhoek B. Case detection rates for central Burma (1962-1972). Int J Le pr, 43: 125-8.

20 Irgens LM. Leprosy in Norway. Lepr Rev, 1980; 51: Suppl 1, 1-130.

21 Jesudasan K, Vijayakumaran P, Pannikar VK, Christian M. Impact of MDT on leprosy as measured by selective indicators. Lepr Rev, 1988; 59: 215-23.

22 Davey TF. Editorial: Common features in rapidly declining leprosy epidemics. Lepr Rev, 1975; 46: 5-8. 